\title{
Pembangunan Sistem Informasi Keuangan Studi Kasus SMK Marsudi Luhur I Yogyakarta
}

\author{
Edward Satya Surya \\ Program Studi Teknik Informatika, Fakultas Teknologi Industri, Universitas Atma Jaya Yogyakarta \\ Kampus III Bonaventura, Jl. Babarsari No. 43, Sleman, 55281, D. I. Yogyakarta \\ E-mail: ess6145@gmail.com
}

Masuk: 20 Mei 2014; Direvisi: 14 Juni 2014; Diterima: 30 Juni 2014

\begin{abstract}
SMK Marsudi Luhur I Yogyakarta needs an information system to manage school financial processes. Financial information system is needed to manage financial proccess in school so financial record can be carried out and well reported too. This system works on a desktop platform and has a centralized data on the server that is connected by a LAN network. Financial information system development begins with an analysis of the system requirements. The functions required is managing income and outcome account, income and outcome budget management, transaction of income and outcome, as well as financial reports. The design processes start by creating ERD and documents design. Coding uses Visual Studio 2008 with C\# programming language and DBMS SQL Server $2008 R 2$ and Crystal Reports. Tests were conducted at school by testing every function in the system. The development of the financial information system meets the need of financial management in SMK Marsudi Luhur I Yogyakarta. The system testing performed by employees SMK Marsudi I Luhur Yogyakarta proves that this system works well.
\end{abstract}

Keywords: Information System, Financial, Marsudi Luhur I Yogyakarta Vocational High School

\begin{abstract}
Abstrak. SMK Marsudi Luhur I Yogyakarta membutuhkan sistem informasi untuk mengelola proses keuangan di sekolah. Sistem informasi keuangan diperlukan untuk mengelola keuangan sekolah sehingga proses keuangan dapat tercatat secara detail dan dapat dilaporkan secara lebih baik. Sistem ini bekerja pada platform desktop dan memiliki data yang terpusat pada server yang terhubung ke jaringan LAN. Pengembangan sistem informasi keuangan dimulai dengan analisis kebutuhan sistem. Fungsi yang diperlukan adalah pengelolaan akun pemasukan dan pengeluaran, pengelolaan anggaran pemasukan dan pengeluaran, pengelolaan transaksi pemasukan dan pengeluaran, serta pencetakan laporan keuangan. Proses desain membuat ERD dan dokumen desain. Coding menggunakan Visual Studio 2008 dengan bahasa pemrograman C\# dan DBMS SQL Server 2008 R2 dan Crystal Reports. Pengujian dilakukan pada sekolah dengan menguji setiap fungsi dalam sistem. Pengembangan sistem informasi keuangan telah memenuhi kebutuhan keuangan di SMK Marsudi Luhur I Yogyakarta. Dengan pengujian sistem keberhasilan 100\% dilakukan oleh karyawan SMK Marsudi Luhur I Yogyakarta membuktikan sistem ini bekerja dengan baik.
\end{abstract}

Kata Kunci: Sistem Informasi, Keuangan, SMK Marsudi Luhur I Yogyakarta

\section{Pendahuluan}

\subsection{Latar Belakang}

Keuangan merupakan hal penting dan perlu diperhatikan dalam suatu organisasi khususnya organisasi yang berkaitan dengan bisnis. Memiliki proses keuangan dan keuangan yang baik dapat memberikan keuntungan yang besar bagi organisasi tersebut. Kegiatan keuangan perlu diatur dan dikendalikan dalam suatu sistem keuangan agar terkoordinasi dengan baik dan rapi. 
Sistem keuangan berfungsi untuk mengatur segala pemasukan dan pengeluaran yang berkaitan dengan proses pada organisasi. Sistem ini akan menghasilkan laporan-laporan dan dokumen-dokumen yang dapat digunakan untuk mengetahui keadaan keuangan organisasi. Sistem keuangan terdiri dari beberapa prosedur dan aturan petunjuk untuk memperjelas proses pengerjaan keuangan sebuah organisasi. Karena setiap organisasi memiliki proses keuangan yang berbeda-beda, maka prosedur dan aturan itu perlu ditentukan dan dikendalikan oleh organisasi dengan kebijakan yang berlaku pada organisasi itu saja.

Organisasi yang besar pasti membutuhkan sistem keuangan yang besar pula. Hal ini disebabkan karena proses transaksi yang terjadi sangat sering dan melibatkan nominal yang besar. Sistem yang besar mempunyai prosedur dan proses bisnis yang banyak dan rumit. Oleh karena itu, dibutuhkan suatu model untuk membantu kinerja keuangan menjadi lebih baik dan dapat terorganisir dengan rapi. Model tersebut dapat disebut dengan sistem informasi keuangan.

Sistem informasi keuangan adalah serangkaian dari satu atau lebih komponen yang saling berelasi dan berinteraksi untuk mencapai suatu tujuan, yang terdiri dari pelaku, serangkaian prosedur, dan teknologi informasi. Pelaku merupakan orang-orang yang terlibat pada sistem termasuk pengembang dan pengguna sistem. Prosedur yang terdapat di sistem adalah proses bisnis yang dapat ditangani oleh sistem dan sesuai dengan kebutuhan perusahaan. Sedangkan teknologi informasi merupakan alat atau aplikasi komputer yang dapat mengakomodir semua kebutuhan bisnis tersebut serta membuat pekerjaan menjadi lebih mudah atau bahkan menjadi otomatis. Selain mempermudah kinerja organisasi, teknologi juga dapat dimanfaatkan untuk hal yang lain, seperti mengamankan data.

Bedasarkan pembahasan di atas, sistem informasi keuangan merupakan suatu hal yang cukup diperlukan dalam proses bisnis di suatu orgasnisasi. Pemanfaatan sistem informasi ini dapat mempermudah proses pencatatan data keuangan serta mempermudah pembuatan laporan keuangan. Kedua hal tersebut membutuhkan ketelitian dan tenaga ekstra jika dilakukan secara manual. Maka dari itu, penulis berinisiatif untuk membuat sistem infomasi keuangan untuk SMK Marsudi Luhur I Yogyakarta.

SMK Marsudi Luhur I Yogyakarta adalah SMK swasta Yogyakarta yang telah berdiri dari tahun 1958. SMK ini merupakan salah satu SMK tertua di Yogyakarta. Sekolah ini juga telah lulus uji ISO 9001:2008 dan telah memiliki SOP (Standar Operasi Prosedur) yang jelas dan baik. Demi kemajuan mutu, SMK Marsudi Luhur I Yogyakarta ingin mengembangkan sistem yang ada dengan membangun suatu sistem informasi yang dapat membantu setiap proses yang terjadi khususnya kegiatan keuangan. Oleh karena itu, penulis menggunakan kasus SMK Marsudi Luhur I Yogyakarta untuk pembangunan Sistem Informasi Keuangan yang sesuai dengan kebutuhan sekolah ini.

Sistem ini dirancang hanya untuk SMK Marsudi Luhur I Yogyakarta, yang berarti disesuaikan dengan proses bisnis yang ada pada SMK Marsudi Luhur I Yogyakarta. Diharapkan pembangunan Sistem Informasi Keuangan yang telah dilakukan diharapkan dapat membantu kinerja SMK Marsudi Luhur I Yogyakarta serta membuat SMK Marsudi Luhur I Yogyakarta menjadi lebih maju dan berkembang.

\subsection{Rumusan Masalah}

Masalah yang muncul bedasarkan latar belakang diatas adalah sebagai berikut: (1) Bagaimana menganalisis kebutuhan fungsionalitas sistem informasi keuangan pada SMK Marsudi Luhur I Yogyakarta? (2) Bagaimana membangun Sistem Informasi Keuangan yang dapat digunakan pada SMK Marsudi Luhur I Yogyakarta secara baik dan benar?

\subsection{Batasan Masalah}

Sistem yang dibuat memiliki beberapa batasan. Batasan tersebut adalah sebagai berikut: (1) Sistem dibuat berbasis dekstop. (2) Data yang digunakan merupakan data yang berasal dari proses bisnis keuangan SMK Marsudiluhur I Yogyakarta pada tahun pelajaran 2012-2013. 


\subsection{Tujuan}

Tujuan yang diharapkan tercapai pada penelitian ini adalah sebagai berikut: (1) Mengetahui kebutuhan fungsionalitas sistem informasi keuangan pada SMK Marsudi Luhur I Yogyakarta. (2) Membangun Sistem Informasi Keuangan yang akan digunakan pada SMK Marsudi Luhur I Yogyakarta secara baik dan benar.

\section{Tinjauan Pustaka}

Bedasarkan penelitian yang telah dilakukan oleh Alsharayri, dkk (2012) tentang peforma sistem informasi Keuangan (Akuntansi) pada rumah sakit swasta di Yordania, sistem informasi keuangan sangat membantu organisasi dalam mengelola keuangan. Pada penelitian ini yang dilakukan hanya dengan kuisoner, menunjukkan bahwa karyawan tidak dapat mengikuti perkembangan sistem sehingga membuat karyawan perlu mempelajari lagi sistem yang digunakan. Oleh karena itu, perlu adanya pendekatan secara lebih mendalam ke pengguna sehingga sistem yang akan dibangun dapat lebih mudah digunakan dan sesuai dengan kemampuan pengguna dan diharapkan karyawan dapat bekerja dengan maksimal. Maka dari itu, sistem yang akan dibuat penulis difokuskan pada SMK Marsudiluhur I Yogyakarta agar menjadi sistem yang dapat memenuhi kebutuhan organisasi secara detail.

Bedasarkan penelitian yang lain yang telah dilakukan oleh Shamszadeh, dkk (2012) tentang Sistem Informasi Keuangan, banyak terdapat permasalahan dalam membuat sistem yang berkaitan dengan keuangan khususnya sistem yang menggunakan teknologi komputer. pembangunan sistem perlu ditinjau secara khusus dengan memperhatikan ancaman keamanan sistem yang dapat membuat sistem bekerja dengan tidak optimal dan dapat membahayakan organisasi pengguna sistem. Penelitian ini berfokus pada tingkah laku dan pendidikan pengguna sehingga belum membahas secara mendalam tentang kehandalan sistem dalam menangani ancaman tersebut. Sistem yang akan dibuat menekankan pada kemudahan pemanfaatan sistem sehingga pengguna dapat lebih mudah berbaur dengan sistem.

Penelitian lainnya yang telah dilakukan oleh Kosarkoska (2010) tentang Sistem Informasi Keuangan pada industri hotel mengangkat masalah fungsi keuangan dan keuangan memerlukan strategi khusus yang optimal untuk memperoleh keberhasilan bisnis. Hal ini tidak hanya berfokus pada pelayan yang baik bagi pemegang saham, tetapi juga meliputi manajemen perusahaan secara strategis guna mencapai keselarasan yang diharapkan. Penelitian yang dilakukan dengan metode analisis dan studi pustaka ini menunjukkan bahwa sistem informasi keuangan sudah menjadi tren pada pelaporan keuangan global tetapi tidak mempertimbangkan pada bagian kecil sistem yaitu pengguna sistem. Penelitian ini terlalu berfokus pada manajemen sistem sehingga permasalahan pada penggua kurang diperhatikan. Padahal pengguna secara langsung merupakan entitas yang paling dekat dengan sistem sehingga lebih mengerti dengan sistem yang ada. Maka dari itu, penulis berusaha mencari informasi dari pengguna sistem sehingga sistem yang akan dibuat dapat memenuhi kebutuhan pengguna dan sesuai dengan pekerjaan yang biasanya telah dilakukan.

Sistem yang serupa juga pernah diteliti oleh Prabhu (2004). Sistem tersebut berupa prototype dan didistribusikan ke seluruh sekolah-sekolah serta pusat-pusat penelitian yang dapat berfungsi sebagai sistem yang dapat membantu kinerja sekolah. Pembangunan prototype ini dapat mengidentifikasi dan mengartikulasikan ruang lingkup dan tantangan penelitian dalam pekerjaan multi disiplin beberapa sekolah. Meskipun demikian, sistem tersebut terlalu global dan sekolah perlu beradaptasi dengan sistem jika ingin menerapkannya. Proses beradaptasi ini dapat menuai permasalahan dan menghabiskan banyak biaya dan waktu.

\section{Dasar Teori}

\subsection{Sistem Informasi}

Sistem informasi adalah suatu sistem di dalam suatu organisasi yang mempertemukan kebutuhan pengolahan transaksi harian yang mendukung fungsi organisasi yang bersifat manajerial dalam kegiatan strategi dari suatu organisasi untuk dapat menyediakan kepada pihak luar tertentu dengan laporan - laporan yang diperlukan (Sutabri, 2008). Hal ini menunjukkan 
bahwa sistem informasi dapat sangat membantu organisasi dalam menyelenggarakan bisnisnya. Pemanfaatan sistem informasi, terutama yang berbasis komputer, dapat mempercepat kinerja karyawan, menambah kualitas ketepatan data, bahkan juga memungkinkan membuat suatu pekerjaan menjadi otomatis.

\subsection{Sistem Informasi Keuangan}

Sistem informasi keuangan merupakan kumpulan sumber daya, seperti manusia dan peralatan yang dirancang untuk mengubah data keuangan dan data lainnya ke dalam informasi, informasi tersebut dikomunikasikan kepada para pembuat keputusan (Bodnar, 2006). Menurut pengertian di atas, sistem informasi keuangan berfokus pada data keuangan dan dapat mengolah data tersebut menjadi informasi yang dapat diterima oleh manajemen organisasi. Informasi keuangan merupakan hal yang perlu diperhatikan dalam organisasi khususnya organisasi yang bergerak pada bidang bisnis. Maka dari itu, perlu adanya sistem yang memanfaatkan teknologi untuk memenuhi kebutuhan informasi keuangan organisasi.

Sistem informasi keuangan bukan hanya diperuntukkan pada perusahaan besar yang mempunyai proses bisnis rumit. Sistem ini juga dapat diterapkan pada organisasi bisnis kecil. Pemanfaatan sistem informasi keuangan dapat disesuaikan dengan kekuatan dan kelemahan usaha kecil dan mampu memajukan usaha dalam bidang keuangan (Haryani, 2012).

\subsection{Manfaat Sistem Informasi Keuangan}

Secara umum, terdapat 3 manfaat sistem informasi keuangan bagi perusahaan: (1) Mengumpulkan dan menyimpan data dari semua aktifitas dan transaksi keuangan perusahaan (2) Memproses data menjadi informasi yang berguna dalam pengambilan keputusan yang memungkinkan bagi pihak manajemen untuk melakukan perencanaan, mengeksekusi perencanaan dan mengontrol aktivitas. (3) Menyediakan kontrol yang cukup untuk menjaga aset dari organisasi, termasuk data. Kontrol ini memastikan bahwa data akan tersedia ketika dibutuhkan dan data tersebut akurat dan dapat dipercaya (Romney \& Steinbart, 2000).

Manfaat lainnya dari sistem informasi keuangan adalah dapat mempengaruhi kinerja organisasi secara langsung (Soudani, 2012) dan juga memenuhi kebutuhan pengguna melalui penerapan kerja keuangan dengan cepat dan dengan usaha minimal, untuk mencapai keunggulan kompetitif di antara organisasi. Selain itu sistem informasi keuangan juga dapat memberikan informasi akurat dengan menunjukkan posisi keuangan untuk pengguna (Wedyan, 2012) serta menghubungkan semua subsistem informasi bisnis serta membuat kinerja perusahaan menjadi lebih baik (Tokić, 2011 \& Spathis, 2008). Penggunaan sistem informasi keuangan juga dapat mempengaruhi secara langsung tata kelola IT sehingga secara tidak langsung menguntungkan perusahaan (Al-Zwyalif, 2013).

\section{Hasil dan Pembahasan \\ 4.1. Analisa Kebutuhan}

Proses keuangan SMK Marsudiluhur I Yogyakarta menggunakan proses yang serupa dengan sistem keuangan yang lainnya. Proses pada sistem informasi keuangan (gambar 1) dapat dijabarkan sebagai berikut: (1) Petugas keuangan memasukan akun-akun keuangan yang dibutuhkan pada transaksi keuangan. (2) Petugas keuangan memasukan rencana anggaran yang akan menjadi pemasukan atau pengeluaran. (3) Petugas keuangan memasukan nilai pemasukan yang didapat dari pembayaran uang SPP dan pemasukan yang lain. Pemasukan disesuaikan dengan akun agar memmudahkan pelaporan. (4) Data pengeluaran dimasukan oleh petugas pada sistem sesuai dengan akun pengeluaran. Pengeluaran ini dapat berupa transfer ke rekening, tunai atau yang lainnya. (5) Kepala sekolah dan orang-orang yang ditunjuk dapat melihat laporan keuangan sesuai dengan pemasukan dan pengeluaran pada periode tertentu. Laporan juga dapat disesuaikan dengan pengguna atau kebutuhan yang lain. Semua proses tersebut masih menggunakan Microsoft Excel dan pencatatan manual.

Sistem Informasi Keuangan untuk SMK Marsudi Luhur I merupakan sistem yang dapat mempermudah kegiatan keuangan pada organisasi. Kegiatan keuangan berupa pengelolaan akun 
pemasukan dan pengeluaran, pengelolaan anggaran pemasukan dan pengeluaran, transaksi bisnis dan laporan keuangan. Pengunaan sistem ini dilakukan oleh staf keuangan sekolah yang bertugas mengelola urusan keuangan seperti pembayaran SPP, gaji guru dan lain-lain.

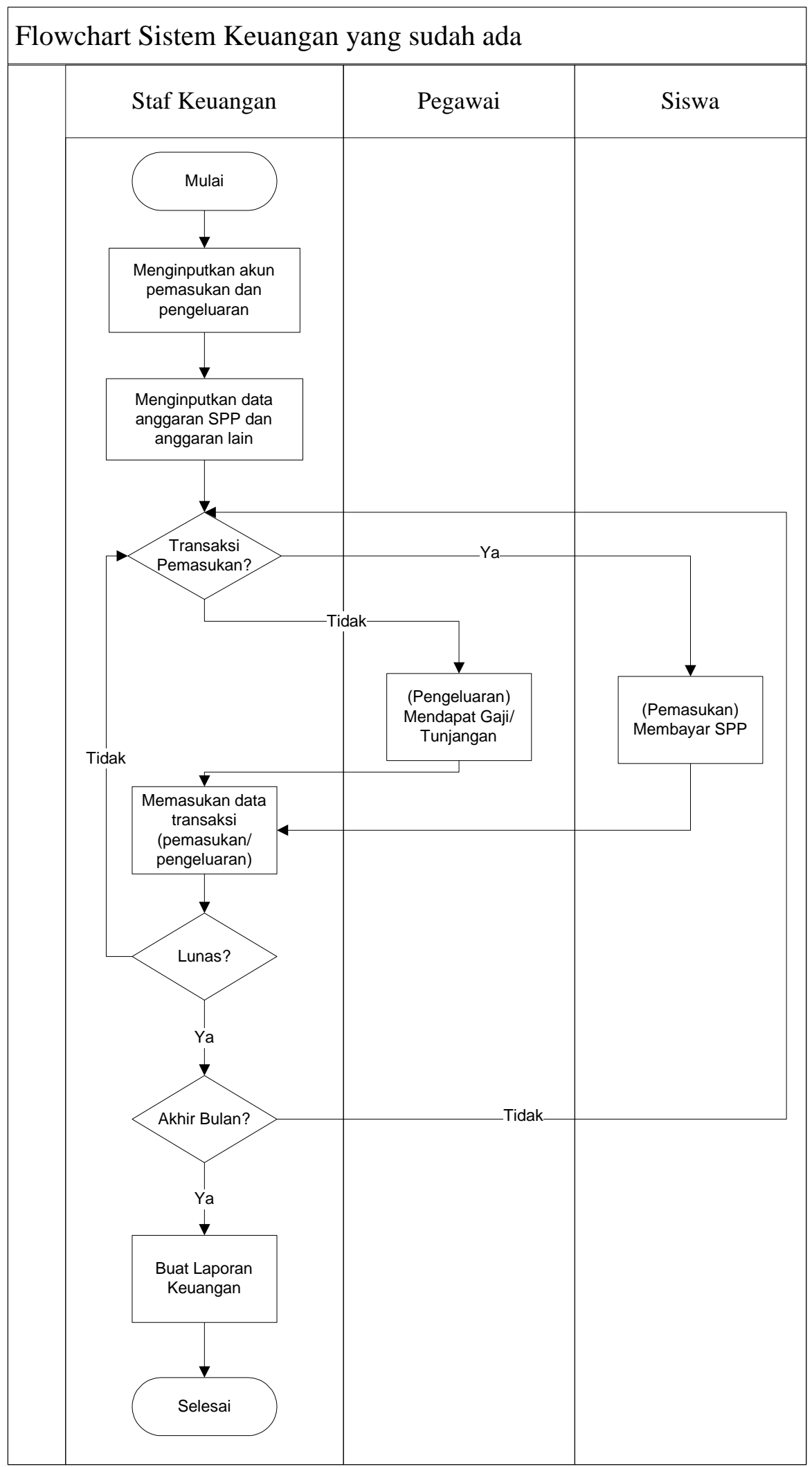

Gambar 1. Flowchart sistem yang sudah ada 


\subsection{Perancangan Sistem}

Use Case Diagram dari perangkat lunak SIKU dapat dilihat pada gambar 2. Sedangkan Entity Relationship Diagram nya dapat dilihat pada gambar 3.

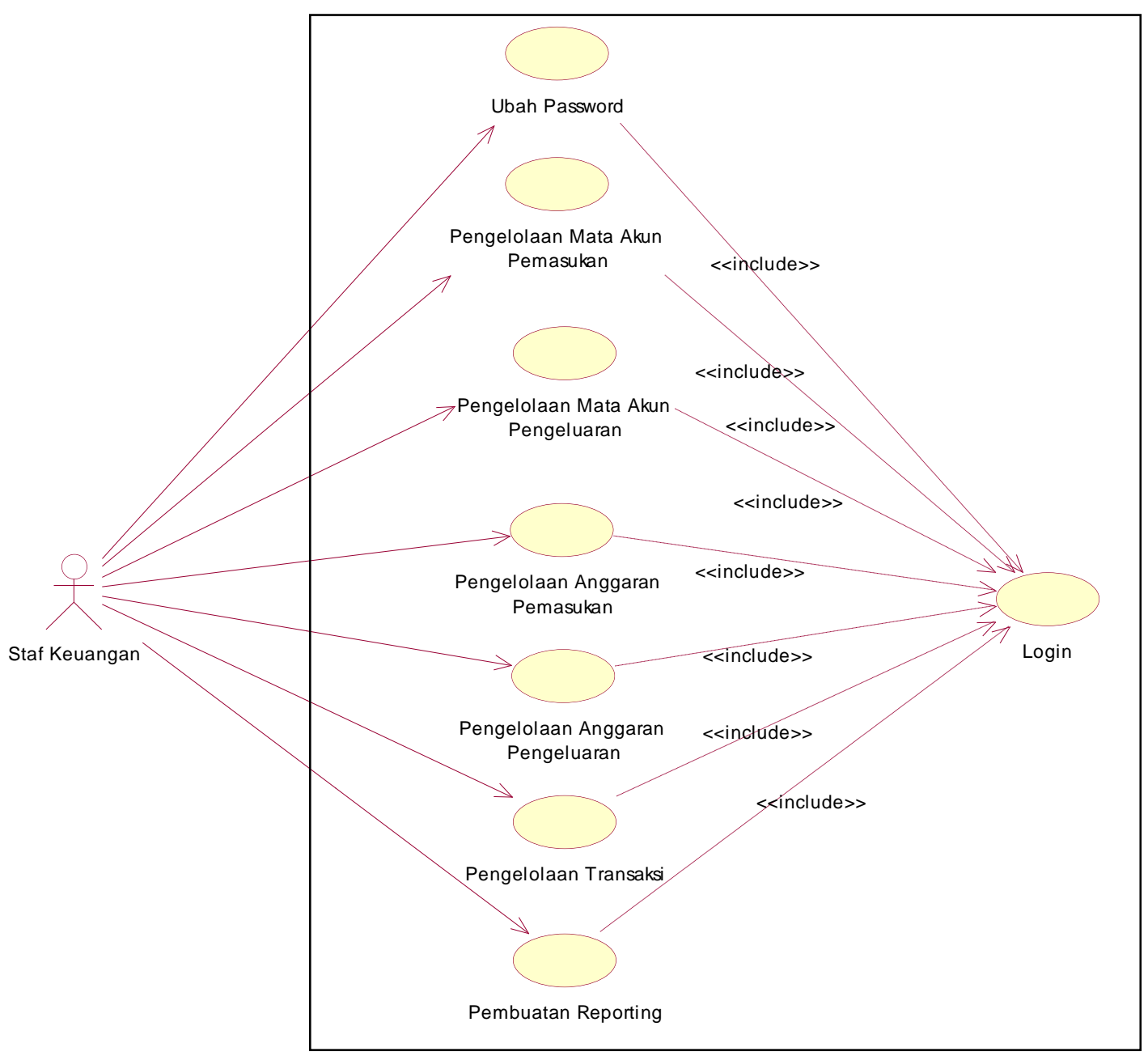

Gambar 2. Use Case Diagram SIKU 


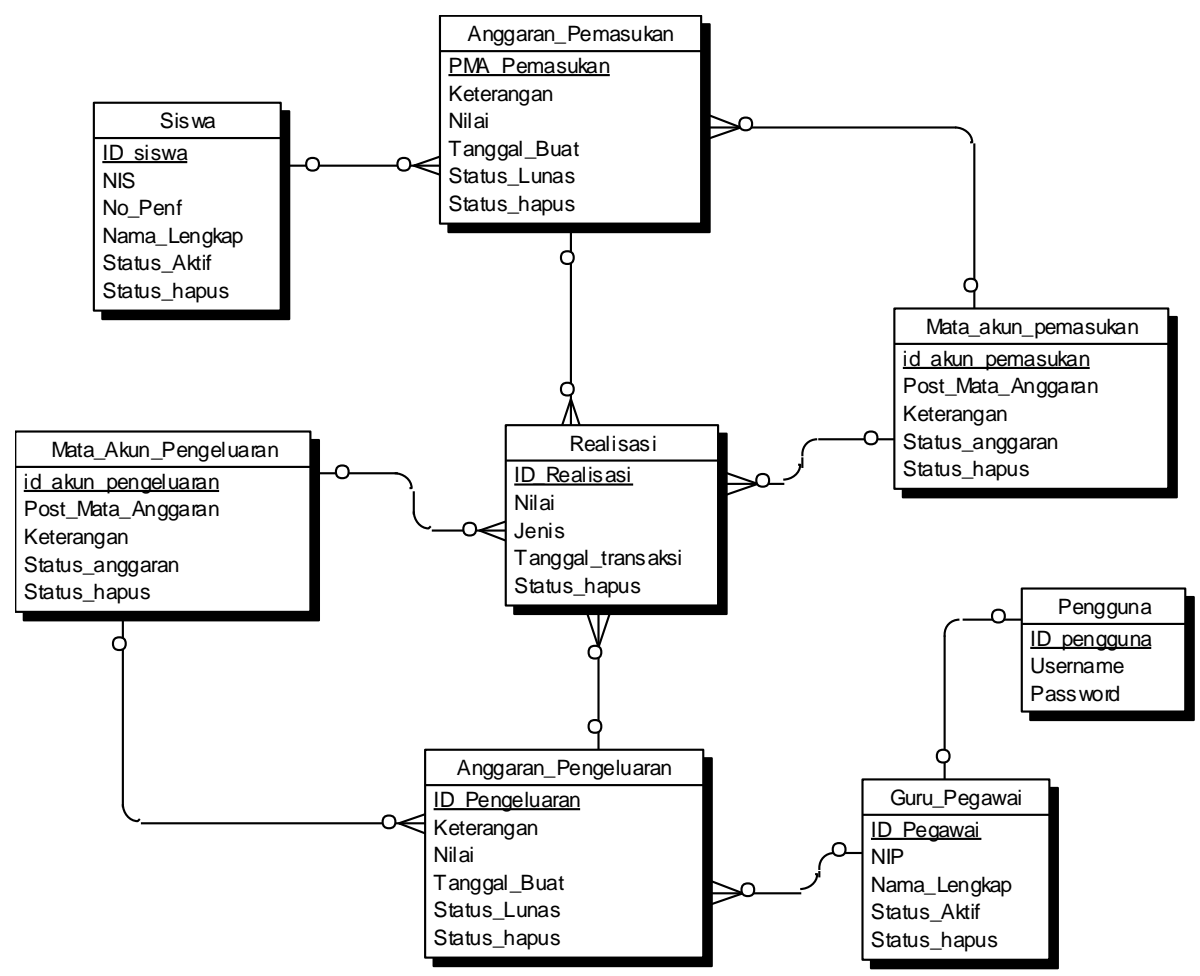

Gambar 3. Entity Relationship Diagram SIKU

\subsection{Implementasi Sistem}

Perangkat lunak Sistem Informasi Keuangan (SIA) untuk SMK Marsudi Luhur I Yogyakarta dibangun dengan menggunakan bahasa pemrograman C\#. Bahasa pemrograman C\# dipilih karena cukup populer dalam pembangunan sistem desktop. Sistem ini memiliki 5 class untuk entity, 4 class untuk control, 18 class untuk User Interface, 5 file dataset, dan 5 Crystal Reports. Pembuatan sistem dilakukan selama kurang lebih 6 bulan dan dikerjakan oleh 1 orang. Beberapa contoh antarmuka sistem dapat dilihat pada gambar 4 sampai dengan gambar 7 .

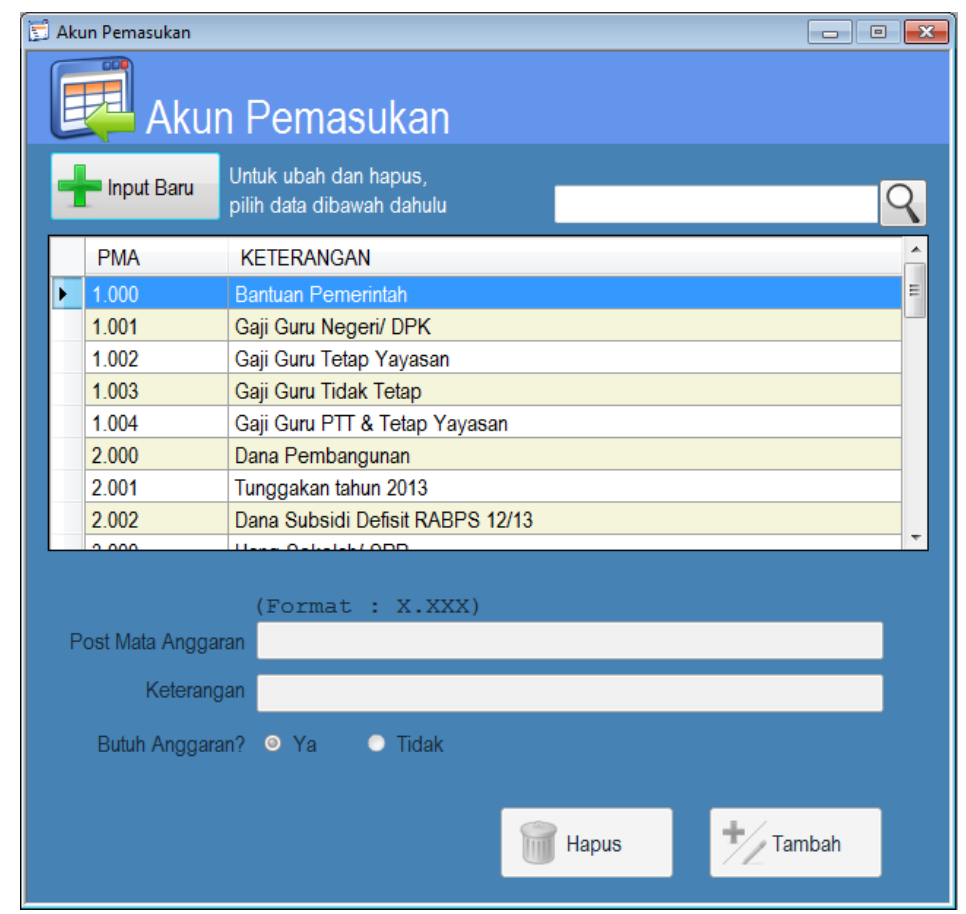

Gambar 4. Antarmuka pengelolaan Akun Pemasukan 
38 Jurnal Buana Informatika, Volume 6, Nomor 1, Januari 2015: 31-40

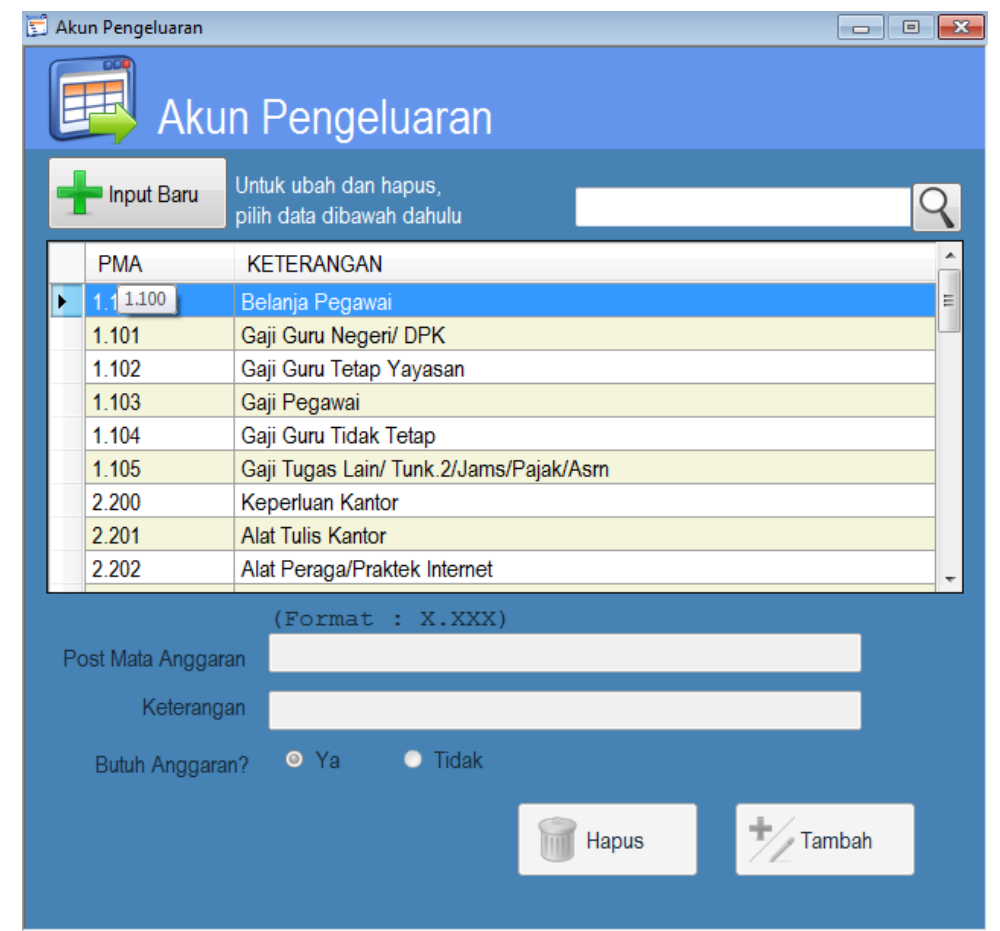

Gambar 5. Antarmuka pengelolaan Anggaran Pengeluaran

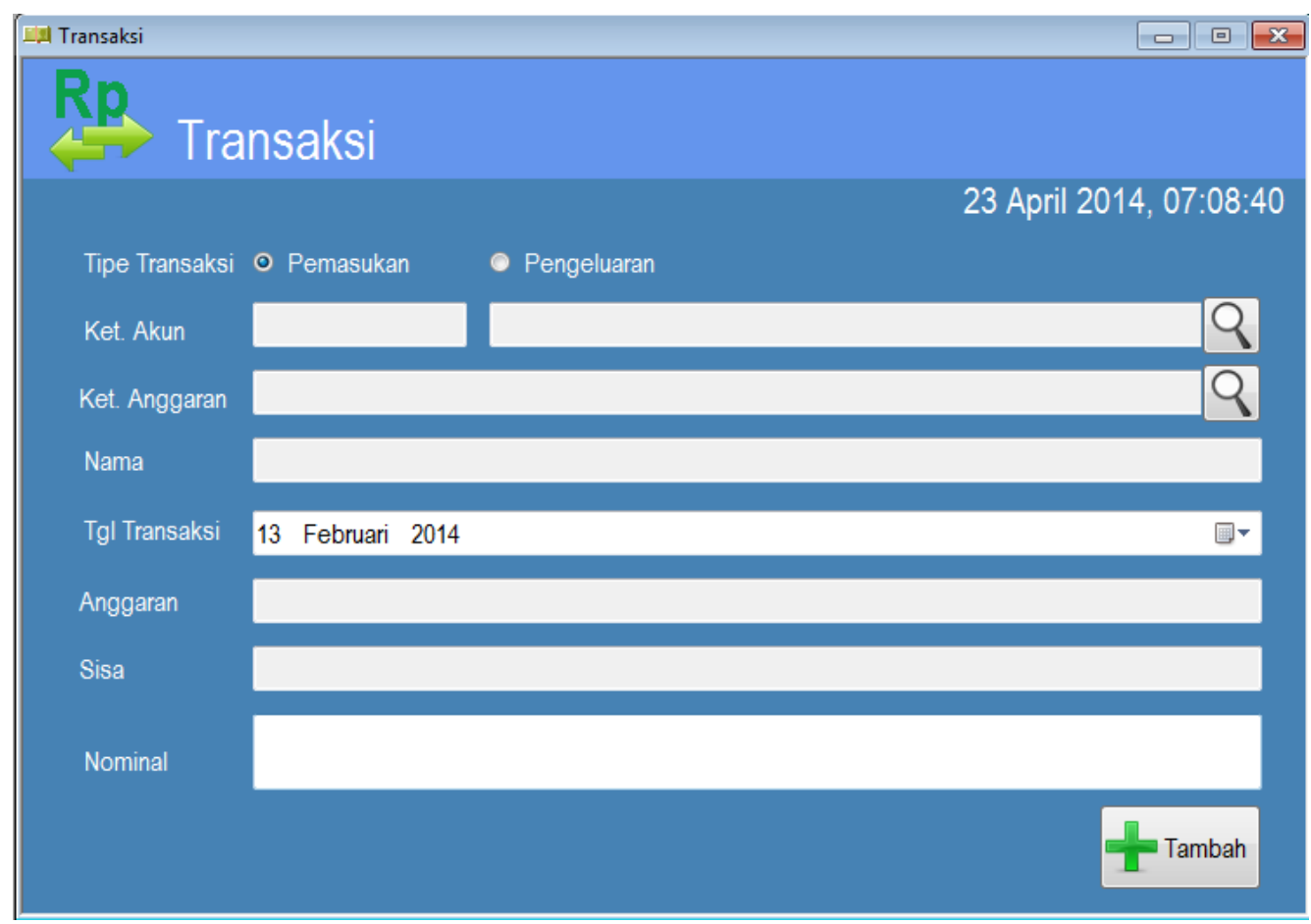

Gambar 6. Antarmuka Tambah Transaksi 


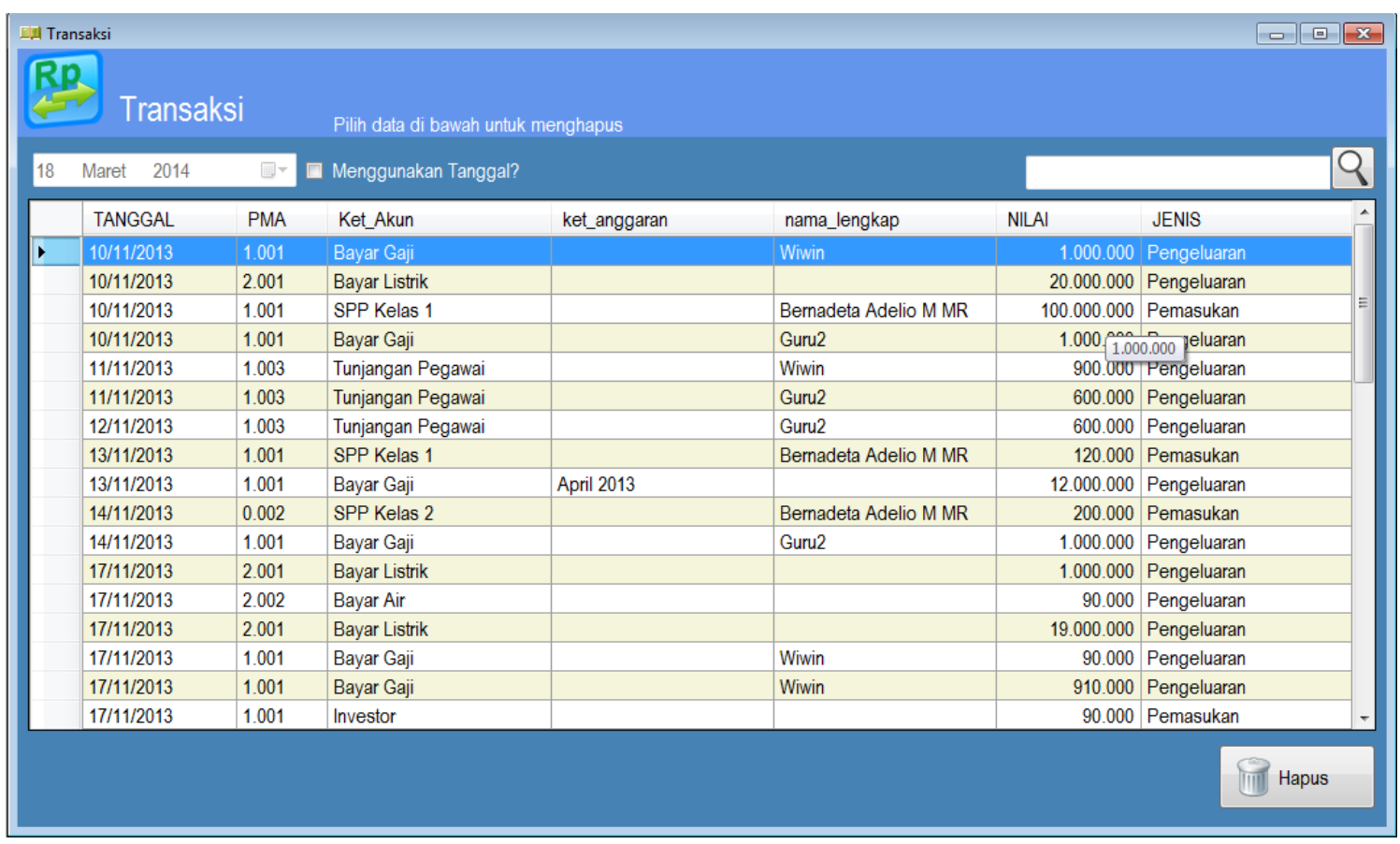

Gambar 7. Antarmuka Lihat Transaksi

\subsection{Hasil Pengujian}

Pengujian dilakukan pada SMK Marsudi Luhur I Yogyakarta pada tanggal 29 Maret 2014. Pengujian melibatkan mahasiswa Atma Jaya, guru dan pegawai SMK Marsudi Luhur I Yogyakarta. Aplikasi dijalankan pada komputer yang ada pada komputer Lab. Informatika Lanjut Universitas Atma Jaya Yogyakarta. Hasil uji menyatakan setiap butir uji telah dapat dilakukan dengan sempurna dan memuaskan pengguna.

\section{Kesimpulan}

Bedasarkan uraian dan pengujian yang telah dilakukan, kesimpulan dari pembangunan sistem ini adalah: (1) Telah berhasil dilakukan analisis kebutuhan fungsionalitas sistem informasi keuangan yaitu pengelolaan mata akun pemasukan dan pengeluaran, anggaran pemasukan dan pengeluaran, transaksi, serta pencetakan laporan keuangan. (2) Sistem Informasi Keuangan untuk SMK Marsudi Luhur I Yogyakarta telah berhasil dibangun dengan benar dan dapat berjalan secara baik.

\section{Referensi}

Alsharayri, Majed. 2012. Evaluating the Performance of Accounting Information Systems in Jordanian Private Hospitals. Journal of Social Sciences, Vol. 8. p74-p78.

Al-Zwyalif, Inaam M. 2013. IT Governance and its Impact on the Usefulness of Accounting Information Reported in Financial Statements. International Journal of Business and Social Science. Vol. 4. p. -

Bodnar, Goerge H. dan William S. Hopwood. 2006. Sistem Informasi Akuntansi, Edisi 9. Yogyakarta : ANDI.

Haryani, Endang. 2012. Accounting System For Small Business In Indonesia (Case Study Convection Business In Tingkir Lor Village). Researchers World, Vol. 3. p104-111.

Kosarkoska, Desa. 2010. The Challenges For Accounting Information System In Hotel Industry. Faculty of Tourism and Hospitality Management in Opatija. Biennial International Congress. Tourism \& Hospitality Industry. p411-426.

Prabhu, Vittal, Small, Salaka \& Panicker. 2004. Information System for Enabling Innovative Process in School Systems. IIE Annual Conference. Proceedings. p1.

Romney, Marshall B. \& Stembart, Paul John.. 2000. Accounting Information System (8th ed.). 
New Jersey : Prentice Hall.

Shamszadeh, Bagher \& Azizi, Abolfazl. 2012. Computerized Accounting Information Systems (CAIS) Versus Security Threats. Journal of Academic Research in Economics, Vol. 4. p69-79.

Soudani, Siamak Nejadhosseini. 2012. The Usefulness of an Accounting Information System for Effective Organizational Performance. International Journal of Economics and Finance, Vol. 4. p136-145.

Spathis, Charalambos \& Ananiadis, John. 2005. Assessing the benefits of using an enterprise system in accounting information and management. Journal of Enterprise Information Management, Vol. 18. p195-210.

Sutabri, Tata. 2005. Sistem Informasi Manajemen. Yogyakarta. Andi.

Tokić, Marija. 2011. Functional Structure Of Entrepreneurial Accounting Information Systems. Annals of the Faculty of Engineering Hunedoara - International Journal of Engineering, Vol. 9. p165-168.

Wedyan, Lu'ay Mohammad Abdel-Rahman. 2012. The Affect of Applying Accounting Information System on the Profitability of Commercial Banks in Jordan (A field study from Management's Viewpoint). Journal of Management Research, Vol. 4. p122-138. 